\title{
Prognostic value of B7-H3 expression in patients with solid tumors: a meta-analysis
}

\author{
Xianyun Zhang ${ }^{1,2, *}$, Chuntao Fang ${ }^{3, *}$, Guangbo Zhang ${ }^{4}$, Fujin Jiang ${ }^{2}$, Lei Wang ${ }^{2}$ and \\ Jianquan Hou ${ }^{1}$ \\ ${ }^{1}$ Department of Urology, First Affiliated Hospital of Soochow University, Suzhou, Jiangsu, China \\ ${ }^{2}$ Department of Urology, The Affiliated Huai'an Hospital of Xuzhou Medical University, The Second People's Hospital of \\ Huai'an, Huai'an, Jiangsu, China \\ ${ }^{3}$ Department of Gynaecology, The Affiliated Huai'an Hospital of Xuzhou Medical University, The Second People's Hospital of \\ Huai'an, Huai'an, Jiangsu, China \\ ${ }^{4}$ Clinical Immunology Laboratory, First Affiliated Hospital of Soochow University, Suzhou, Jiangsu, China \\ *These authors contributed equally to this work
}

Correspondence to: Jianquan Hou, email: houjq01@163.com

Keywords: B7-H3, solid tumor, survival, prognostic biomarker, meta-analysis

Received: December 20, $2016 \quad$ Accepted: September 03, $2017 \quad$ Published: September 21, 2017

Copyright: Zhang et al. This is an open-access article distributed under the terms of the Creative Commons Attribution License 3.0 (CC BY 3.0), which permits unrestricted use, distribution, and reproduction in any medium, provided the original author and source are credited.

\section{ABSTRACT}

Increasing evidence suggests B7-H3 is aberrantly expressed in various cancers, though its prognostic significance in solid tumors remains controversial. We therefore performed a meta-analysis to clarify the prognostic value of B7-H3 expression in human solid tumors. The PubMed and Embase databases were searched, and 28 studies involving 4623 patients were ultimately included in the analysis. Hazard ratios (HRs) with $95 \%$ confidence intervals (CIs) were utilized as effect estimates to evaluate the association between B7-H3 expression and overall survival (OS), progressionfree survival (PFS) and recurrence-free survival (RFS). The pooled results showed B7-H3 was associated with poor OS (HR $=1.58 ; 95 \%$ CI: $1.32-1.90 ; P<0.00001)$ and PFS (HR $=1.67 ; 95 \%$ CI: $1.05-2.65 ; P=0.031)$, but not RFS (HR $=1.17 ; 95 \%$ CI: $0.89-1.53 ; P=0.267$ ). These results suggest $B 7-\mathrm{H} 3$ is a negative predictor of OS and PFS in patients with solid tumors. B7-H3 may thus be a useful prognostic biomarker and therapeutic target for human solid tumors. However, further studies will be needed to more precisely determine the prognostic value of B7 H3 expression.

\section{INTRODUCTION}

Cancer has been the leading cause of worldwide mortality for many years and is a global health problem [1]. Despite tremendous advances in recent decades with regard to diagnostic techniques and therapeutic options, the prognosis of many cancers remains poor, especially in late stages. Clinicopathologic characteristics such as pathological grade and clinical stage are the main prognostic factors currently being used, but these parameters are often not reliably predictive of individual clinical outcomes. Therefore, identification of novel tumor biomarkers that can better predict cancer progression and prognosis is of vital importance.

B7-H3 (B7 homolog 3 protein) is a transmembrane glycoprotein and a member of the B7 family of proteins that was first described during analysis of a human dendritic cell (DC)-derived cDNA library [2]. B7-H3 has a critical function in antitumor immune responses [3], and evidence shows that $\mathrm{B} 7-\mathrm{H} 3$ possesses both co-stimulatory and co-inhibitory capacities in different tumor contexts. In addition, B7-H3 plays a nonimmunological role in promoting cancer invasion and progression.

Overexpression of B7-H3 has been described in several cancers, and it was shown that B7-H3 expression is associated with clinicopathological factors and with prognosis in these cancers [4-13]. In some tumor types, high expression of B7-H3 has been linked to a poor prognosis, while in others the opposite relationship has been observed. Wu et al. [12] reported that B7$\mathrm{H} 3$ expression correlates with a favorable prognosis 
in gastric cancer patients and suggested B7-H3 may promote an immune response. By contrast, Sun et al. [14] found that B7-H3 expression in non-small-cell lung cancer (NSCLC) correlates inversely with the number of tumor-infiltrating lymphocytes, which has the effect of promoting lymph node metastasis. Similarly, B7-H3 expression was identified as a poor prognostic factor in prostate cancer [15]. Thus, reports on the ability of $\mathrm{B} 7-\mathrm{H} 3$ to predict outcomes in various cancers are inconsistent. We therefore conducted a meta-analysis to assess the prognostic value of $\mathrm{B} 7-\mathrm{H} 3$ expression in cancer patients.

\section{RESULTS}

\section{Characteristics of identified studies}

Twenty-eight studies published between 2007 and 2017 were included in our meta-analysis (Figure 1). A total of 4623 participants were analyzed to evaluate the relationship between B7-H3 expression and the prognoses of various tumors. Of this group, 3170 patients were positive for $\mathrm{B} 7-\mathrm{H} 3$ expression. The patients came from China, Japan, Austria, Norway, America and Germany and had been diagnosed with various cancers, including endometrial cancer, gastric carcinoma, cervical cancer, oral cancer, pancreatic cancer, osteosarcoma, esophageal cancer, colorectal cancer, breast cancer, hepatocellular carcinoma, ovarian carcinoma, lung cancer, prostate cancer, renal cell carcinoma (RCC), urothelial carcinoma of the bladder (UCB) and gallbladder cancer. Seven studies examined Caucasians, and 21 examined Asians. Twenty-six studies reported OS, 4 studies reported PFS, and 4 studies reported RFS. HRs and $95 \%$ CIs were directly reported in 15 studies and were calculated from survival curves in the other 13 studies. Cut-off values were different among the studies. The main characteristics of our included studies are presented in Table 1.

\section{B7-H3 expression and OS}

Twenty-six studies evaluating 3690 patients were submitted to OS analysis. Because statistical heterogeneity was observed among these studies $\left(I^{2}=47.1 \%, P_{\text {heterogeneity }}\right.$ $=0.005$ ), we used a random effects model to pool their HRs. The main results of this meta-analysis are presented in Table 2. The pooled analysis showed that B7-H3 overexpression was significantly associated with worse OS in patients with solid tumors (pooled HR $=1.58 ; 95 \%$ $\mathrm{CI}=1.32-1.90 ; P<0.00001$ ) (Figure 2). Excluding two studies $[6,12]$ resolved the heterogeneity $\left(I^{2}=15.4 \%\right.$, $P_{\text {heterogeneity }}=0.248$ ) (Figure 2), but we did not find sufficient clinical heterogeneity to justify their exclusion. To explore the source of the identified heterogeneity in these studies, we performed subgroup analyses by ethnicity, cancer type and source of HR. The subgroup analysis for ethnicity showed that B7-H3 expression was significantly associated with worse OS in Asians (pooled $\mathrm{HR}=1.67 ; 95 \% \mathrm{CI}=1.38-2.04 ; P<0.00001)$, but not in Caucasians (pooled HR $=1.18 ; 95 \% \mathrm{CI}=0.84-1.66$; $P=0.35$ ); however, this difference was not statistically significant $\left(P_{\mathrm{D}}=0.08\right)$ (Figure 3$)$. The subgroup analysis based on tumor type showed that B7-H3 expression was significantly associated with worse OS for lung cancer $(\mathrm{HR}=1.94 ; 95 \% \mathrm{CI}=1.31-2.87, P=0.001)$, esophageal cancer $(\mathrm{HR}=2.07 ; 95 \% \mathrm{CI}=1.19-3.59, P=0.010)$ and other cancers including endometrial cancer, breast cancer, cervical cancer, oral cancer, osteosarcoma, hepatocellular cancer, ovarian cancer, RCC, UCB and gallbladder cancer (pooled $\mathrm{HR}=1.53 ; 95 \% \mathrm{CI}=1.18-1.99 ; P=0.001$ ). However, there was no significant relationship between B7-H3 expression and OS in gastric cancer $(\mathrm{HR}=$ $0.80 ; 95 \% \mathrm{CI}=0.19-3.36 ; P=0.759)$, pancreatic cancer $(\mathrm{HR}=1.38 ; 95 \% \mathrm{CI}=0.74-2.55 ; P=0.309)$, or colorectal cancer $(\mathrm{HR}=1.02 ; 95 \% \mathrm{CI}=0.71-1.47$; $P=0.901)$. Overall, the differences among cancer types were not statistically significant $\left(P_{\mathrm{D}}=0.16\right)$ (Figure 3$)$. Lastly, the subgroup analysis based on source of HR showed that differences between reported HRs and those based on survival curves were not statistically significant $\left(P_{\mathrm{D}}=0.06\right)$ (Figure 3$)$. To assess the stability of our results, we performed a sensitivity analysis by sequential omission of individual studies using a random effects model and found that the results were not clearly influenced by any single study (Supplementary Figure 1). We also evaluated the publication bias of all included studies using funnel plots and Egger's and Begg's tests. Visual inspection of the funnel plots (Supplementary Figure 2) revealed no evidence of publication bias, which was confirmed by Begg's test $(P=0.186)$ and Egger's tests $(P=0.100)$.

\section{B7-H3 expression and PFS}

Four studies evaluating 1351 patients underwent PFS analysis. Due to obvious statistical heterogeneity among these studies $\left(P_{\text {heterogeneity }}=0.062, I^{2}=59.1 \%\right)$, we used a random effects model to pool their HRs. Our metaanalysis of these 4 studies revealed that $\mathrm{B} 7-\mathrm{H} 3$ expression was associated with poor $\mathrm{PFS}(\mathrm{HR}=1.67,95 \% \mathrm{CI}=1.05-$ $2.65, P=0.031)$ (Figure 4).

\section{B7-H3 expression and RFS}

Four studies evaluating 1191 patients underwent RFS analysis. A fixed effects model was used to pool their HRs because no obvious heterogeneity was observed among these studies $\left(P_{\text {heterogeneity }}=0.217 ; I^{2}=32.6 \%\right.$ ). Our meta-analysis of these 4 studies showed that B7-H3 expression was not associated with RFS (HR $=1.17$, $95 \% \mathrm{CI}=0.89-1.53, P=0.267)($ Figure 5$)$. 
Table 1: Main characteristics of the studies in this meta-analysis

\begin{tabular}{|c|c|c|c|c|c|c|c|c|c|c|}
\hline Author & Year & Country & Cancer & $\begin{array}{c}\text { Case } \\
\text { number }\end{array}$ & $\begin{array}{c}\text { No. of } \\
\text { B7-H3(+) }\end{array}$ & $\begin{array}{l}\text { Detection } \\
\text { method }\end{array}$ & Cut-off & $\begin{array}{c}\text { Source of } \\
\text { HR }\end{array}$ & $\begin{array}{l}\text { Outcome } \\
\text { measures }\end{array}$ & $\begin{array}{l}\text { Follow-up } \\
\text { (months) }\end{array}$ \\
\hline Xu et al. [6] & 2010 & China & NSCLC & 102 & 71 & $\mathrm{IHC}$ & NR & Reported & OS & $15-50$ \\
\hline Brunner et al. [13] & 2012 & Austria & Endometrial & 99 & 29 & $\mathrm{IHC}$ & IHS $\geq 9$ & $\mathrm{SC}$ & OS & $57(24-89)$ \\
\hline Wu et al. [12] & 2006 & China & Gastric & 102 & 60 & $\mathrm{IHC}$ & $\begin{array}{l}\text { Average positive } \\
\text { cell ratio }>20 \%\end{array}$ & Reported & OS & NR \\
\hline Huang et al. [16] & 2016 & China & Cervical & 108 & 78 & IHC & IRS $\geq 3$ & Reported & OS & $36-96$ \\
\hline Chen et al. [17] & 2015 & China & Oral & 72 & 48 & $\mathrm{IHC}$ & NR & $\mathrm{SC}$ & OS & NR \\
\hline $\mathrm{Xu}$ et al. [18] & 2013 & China & Pancreatic & 45 & 35 & $\mathrm{IHC}$ & IRS $>3$ & $\mathrm{SC}$ & OS & $29.6(8-64)$ \\
\hline Wang et al. [19] & 2013 & China & Osteosarcoma & 61 & 37 & IHC & IRS $>3$ & $\mathrm{SC}$ & OS & $60(24-87.60)$ \\
\hline Wang et al. [20] & 2016 & China & Esophageal & 66 & 44 & IHC & IRS $>3$ & Reported & OS & NR \\
\hline Chen et al. [21] & 2015 & China & Esophageal & 174 & 97 & IHC & H-score $>185$ & Reported & OS & NR \\
\hline Mao et al. [22] & 2013 & China & Colorectal & 98 & 45 & IHC & $\begin{array}{l}\text { Percentage of stained } \\
\text { lymphocytes }>20 \%\end{array}$ & $\mathrm{SC}$ & OS & NR \\
\hline Martin Loos [23] & 2009 & Germany & Pancreatic & 68 & 28 & $\mathrm{IHC}$ & IRS $>3$ & $\mathrm{SC}$ & OS & $23(2-44)$ \\
\hline Maeda et al. [24] & 2014 & Japan & Breast & 90 & 52 & $\mathrm{IHC}$ & IRS $>3$ & Reported & OS/RFS & $67(7.8-90.5)$ \\
\hline Sun et al. [25] & 2012 & China & Hepatocellular & 240 & 168 & $\mathrm{IHC}$ & $\begin{array}{l}\text { IRS: } \\
2 \text { and } 3\end{array}$ & $\mathrm{SC}$ & OS/RFS & $39(1.5-95.0)$ \\
\hline Arigami et al. [26] & 2011 & Japan & Gastric & 95 & 48 & qRT-PCR & NR & Reported & OS & $24(1-74)$ \\
\hline Zang et al. [15] & 2007 & USA & Prostate & 803 & 746 & $\mathrm{IHC}$ & NR & Reported & PFS & $84(63.6-99.6)$ \\
\hline Zang et al. [10] & 2010 & USA & Ovarian & 93 & 41 & IHC & IHS $>50$ & $\mathrm{SC}$ & OS & $\begin{array}{c}\text { Low stage: } \\
\text { 96(7.2-306) High } \\
\text { stage: } \\
12(4.8-94.8)\end{array}$ \\
\hline Chen et al. [27] & 2014 & China & Pancreatic & 63 & 43 & $\mathrm{IHC}$ & $\begin{array}{l}\text { Stained tumor cells } \\
\quad>10 \%\end{array}$ & $\mathrm{SC}$ & OS & NR \\
\hline Jin et al. [28] & 2015 & China & NSCLC & 110 & 60 & IHC & NR & $\mathrm{SC}$ & OS & $6-60$ \\
\hline Liu et al. [29] & 2012 & Norway & Prostate & 130 & 70 & IHC & NR & Reported & PFS/RFS & $84(14-279)$ \\
\hline Mao et al. [30] & 2014 & China & NSCLC & 128 & 89 & IHC & IRS $\geq 2$ & Reported & OS & $53.3(40.3-74)$ \\
\hline Zhou et al. [31] & 2014 & China & Colorectal & 104 & 59 & IHC & NR & $\mathrm{SC}$ & OS & NR \\
\hline $\begin{array}{l}\text { Boorjian } \\
\text { et al. [32] }\end{array}$ & 2008 & USA & $\mathrm{UCB}$ & 318 & 222 & $\mathrm{IHC}$ & $\begin{array}{l}\text { Stained tumor cells } \\
\quad>10 \%\end{array}$ & Reported & OS/PFS & $\geq 120$ \\
\hline $\begin{array}{l}\text { Ingebrigtsen } \\
\text { et al. [33] }\end{array}$ & 2014 & Norway & Colorectal & 731 & 637 & $\mathrm{IHC}$ & NR & $\mathrm{SC}$ & OS/RFS & $116.4(62.4-207.6)$ \\
\hline Luo et al. [34] & 2017 & China & Lung & 46 & 37 & $\mathrm{IHC}$ & $\begin{array}{c}\text { Percentage of } \\
\text { immunoreactivity } \\
>30 \%\end{array}$ & Reported & OS & NR \\
\hline Song et al. [35] & 2016 & China & Esophageal & 100 & 66 & $\mathrm{IHC}$ & Staining score $>3$ & Reported & OS/PFS & $36(5.2-96)$ \\
\hline Fukuda et al. [36] & 2016 & China & $\mathrm{RCC}$ & 181 & 90 & ELISA & NR & Reported & OS & $31(3-100)$ \\
\hline Liu et al. [37] & 2016 & China & Gallbladder & 126 & 84 & $\mathrm{IHC}$ & $\begin{array}{l}\text { Stained tumor cells } \\
>10 \%\end{array}$ & $\mathrm{SC}$ & OS & NR \\
\hline $\begin{array}{l}\text { Inamura } \\
\text { et al.[38] }\end{array}$ & 2017 & Japan & Lung & 270 & 86 & IHC & $\begin{array}{c}\text { Intensity } 1 \geq 50 \% \text { or } \\
\text { intensity } 2 \geq 10 \%\end{array}$ & Reported & OS & NR \\
\hline
\end{tabular}

NSCLC: non-small cell lung cancer; UCB: urothelial carcinoma of the bladder; RCC: renal cell carcinoma; IHC: immunohistochemistry; ELISA: enzymelinked immunosorbent assay; OS: overall survival; PFS: progression-free survival; RFS: recurrence-free survival; NR: no report; SC: survival curve; IRS: immunoreactivity score; IHS: immunohistochemical score; HR: hazard ratio; qRT-PCR: quantitative real-time fluorescence polymerase chain reaction.

\section{DISCUSSION}

B7-H3, a member of the B7 family, was recently identified as an important co-stimulatory molecule that can be induced in B cells, T cells and DCs by a varity of inflammatory cytokines [2]. Although B7-H3 mRNA expression has been widely detected in human tissues, B7-H3 protein has rarely been found in normal tissues; instead, it is commonly detected on the surface of tumor cells [2]. Moreover, B7-H3 expression in tumor cells is associated with their migration, invasion and metastasis, ultimately leading to cancer progression $[39,40]$. The precise physiological function of $\mathrm{B} 7-\mathrm{H} 3$ remains unclear. One early study showed that human B7-H3 functions as a co-stimulator of CD4+ and CD8 $+\mathrm{T}$ cells, promoting $\mathrm{T}$ cell proliferation and cytokine production in vitro [41]. However, most available data support the notion that B7-H3 inhibits T cell activation and proliferation [4143]. Specifically, both the immunoglobulin-V-like and immunoglobulin-C-like forms of human B7-H3 inhibit 
$\mathrm{T}$ cell proliferation and reduce cytokine production in response to $\mathrm{CD} 3 / \mathrm{CD} 28$-mediated co-stimulatory activation [43]. These findings indicate that B7-H3 can act as both a $\mathrm{T}$ cell activator and inhibitor.

By interfering with signaling pathways activated in non-immunological systems, B7-H3 promotes tumor progression, chemosensitivity and cancer metastasis. In the absence of lymphoid cells, Saran-mediated downregulation of B7-H3 significantly inhibited cancer cell migration and invasion, which suggests B7-H3 accelerates cancer progression via an unknown nonimmunological mechanism [44]. B7-H3 expression correlates negatively with miR-29 levels, and the miR-29 binding site on B7-H3 mRNA is evolutionarily conserved, suggesting that a micro-regulatory mechanism influences B7-H3 expression profile at the mRNA and protein levels [45]. B7-H3 also appears to be involved in the Jak/Stat-3 pathway, which participates in multiple steps of metastasis, including invasion, survival, self-renewal, angiogenesis and immune evasion [46]. As Stat-3 is a convergence point for numerous signaling pathways and a valuable target for therapeutic intervention, a possible link between Stat3 and B7-H3 is of great interest.

Findings regarding the prognostic significance of B7-H3 in tumors have been controversial. Most studies suggested that high levels of B7-H3 expression in tumor cells were associated with disease progression and prognosis $[8,10,11,15,25]$, but some reported no correlation between $\mathrm{B} 7-\mathrm{H} 3$ expression and tumor prognosis $[47,48]$. Our results indicated that B7-H3 is highly expressed in 16 types of human cancer, and that high expression of B7-H3 is associated with poorer OS and PFS. However, our subgroup analysis showed that high B7-H3 expression was associated with poor OS in most cancers, but not gastric carcinoma, pancreatic cancer or colorectal cancer. The lack of consistency of these results may reflect differences in the methodologies used or differences in the function of B7-H3 in different cancers [16]. Although investigations have demonstrated the clinical significance of B7-H3 in different cancers, specific cognate receptors for $\mathrm{B} 7-\mathrm{H} 3$ have not been elucidated. The differing opposing effects of B7-H3 in different tumors may be associated with actions via different receptors, though this remains to be determined.

PD-L1 (B7-H1), another B7 family protein, suppresses immune responses by binding with $\mathrm{PD}-1$ on $\mathrm{T}$ cells. Blocking the PD-1/PD-L1 pathway has led to significant clinical successes in a variety of cancers [49-51]. The expression pattern of B7-H3 and its functions differ from those of B7-H1. B7-H3 is mainly expressed on tumor

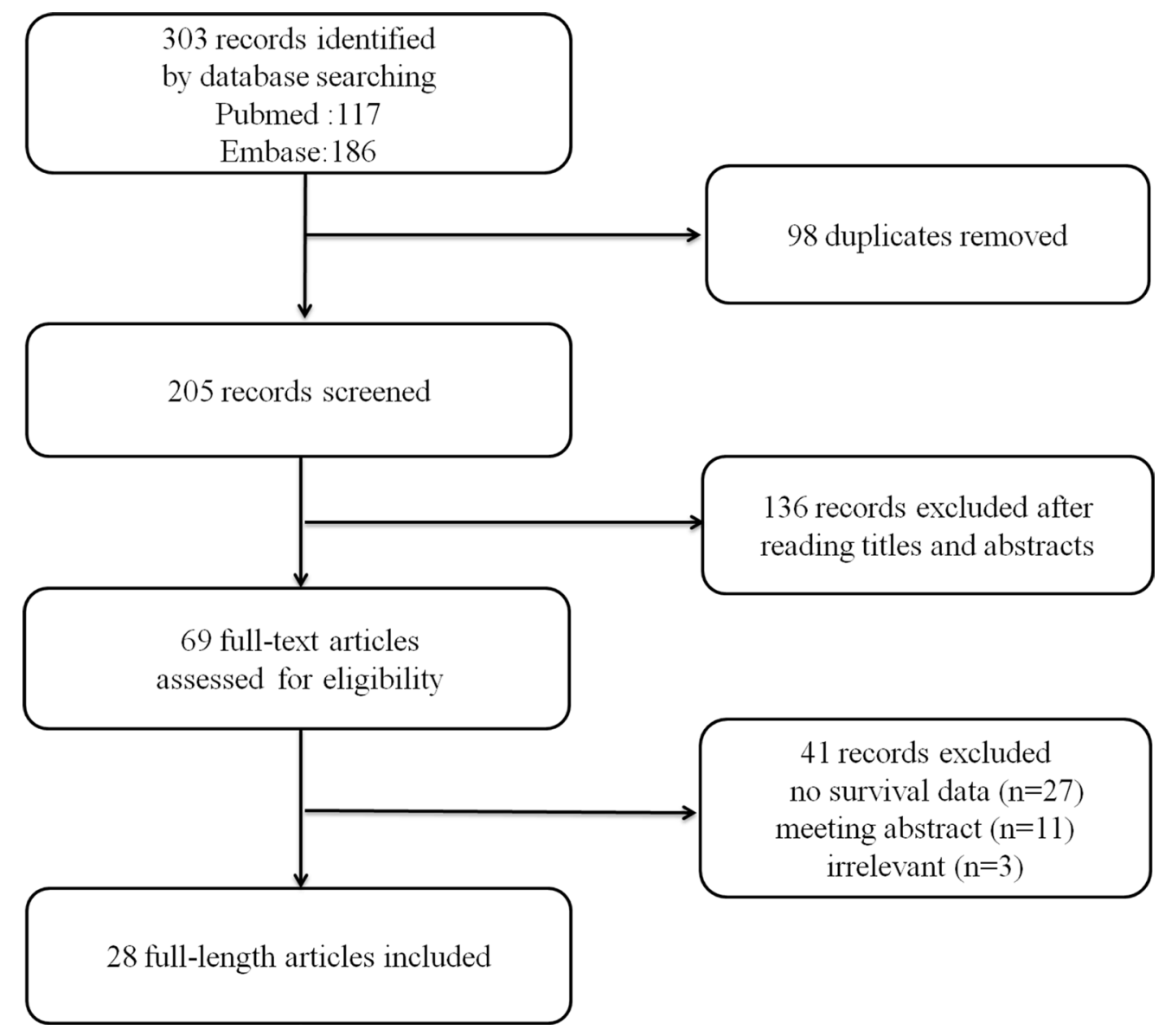

Figure 1: Flow diagram for the selection of studies in the meta-analysis. 
Table 2: Pooled HRs for overall survival and subgroup analysis of B7-H3 expression in cancer patients

\begin{tabular}{|c|c|c|c|c|c|c|c|c|}
\hline & \multirow{2}{*}{$\begin{array}{l}\text { No. of } \\
\text { study }\end{array}$} & \multirow{2}{*}{$\begin{array}{c}\text { No. of } \\
\text { patients }\end{array}$} & \multicolumn{2}{|c|}{ Random effects model } & \multicolumn{2}{|c|}{ Heterogeneity } & \multirow{2}{*}{$P_{D}$ value } & \multirow{2}{*}{$P$ value } \\
\hline & & & Pooled HR & $95 \% \mathrm{CI}$ & $P$ value & $I^{2}$ & & \\
\hline OS & 26 & 3690 & 1.58 & $1.32-1.90$ & 0.005 & $47.1 \%$ & & $<0.00001$ \\
\hline Ethnicity & & & & & & & 0.08 & \\
\hline Caucasian & 5 & 1309 & 1.18 & $0.84-1.66$ & 0.264 & $23.5 \%$ & & 0.350 \\
\hline Asian & 21 & 2381 & 1.67 & $1.38-2.04$ & 0.015 & $44.5 \%$ & & $<0.00001$ \\
\hline Tumor type & & & & & & & 0.16 & \\
\hline Lung & 5 & 656 & 1.94 & $1.31-2.87$ & 0.009 & $70.3 \%$ & & 0.001 \\
\hline Pancreatic & 3 & 176 & 1.38 & $0.74-2.55$ & 0.449 & 0 & & 0.309 \\
\hline Gastric & 2 & 197 & 0.80 & $0.19-3.36$ & 0.007 & $86.2 \%$ & & 0.759 \\
\hline Colorectal & 3 & 933 & 1.02 & $0.71-1.47$ & 0.559 & 0 & & 0.901 \\
\hline Esophageal & 3 & 340 & 2.07 & $1.19-3.59$ & 0.112 & $54.4 \%$ & & 0.010 \\
\hline Other & 10 & 1388 & 1.53 & $1.18-1.99$ & 0.284 & $17.3 \%$ & & 0.001 \\
\hline Source of HR & & & & & & & 0.06 & \\
\hline Reported & 13 & 1780 & 1.80 & $1.37-2.36$ & 0.0003 & $66.5 \%$ & & $<0.0001$ \\
\hline $\mathrm{SC}$ & 13 & 1910 & 1.29 & $1.05-1.59$ & 0.729 & 0 & & 0.014 \\
\hline
\end{tabular}

OS: Overall survival; PFS: progression-free survival; RFS: recurrence-free survival; HR: hazard ratio; CI: confidence interval; PD: $P$ value for subgroup difference; SC: survival curve.

cells and in the vasculature, while PD-L1 is expressed in immune cells, normal cells, and tumor cells [52]. B7-H1 expression in tumors often correlates with poor prognosis in cancer patients [53-55].

In addition to its immunological effects, B7-H3 can also promote cancer cell aggressiveness through various non-immunological pathways. Recently, antibodies targeting $\mathrm{B} 7-\mathrm{H} 3$ have been tested in several phase I/II clinical trials, and the results indicate $\mathrm{B} 7-\mathrm{H} 3$ is a promising target for future cancer immunotherapy. In addition, the relationship between B7-H1 and B7-H3 has been studied in some cancers. Chen et al. [27] showed that B7-H1 and B7-H3 promote pancreatic cancer progression, and their coexpression could be a valuable prognostic indicator. Mao et al. [30] found a positive correlation between expression of B7-H1 and B7-H3 in NSCLC and showed that expression of the two proteins is associated with poorer OS in patients with NSCLC. These findings suggest that treatments targeting $\mathrm{B} 7-\mathrm{H} 3$ and $\mathrm{B} 7-\mathrm{H} 1$ together may be a potential option for cancer immunotherapy.

There are several important implications of our meta-analysis. First, the results showed that B7-H3 overexpression is related to adverse OS and PFS in human solid tumors, indicating that B7-H3 may be a useful prognostic biomarker and therapeutic target for these tumors. Second, subgroup analysis based on cancer type showed that high B7-H3 expression is associated with poor OS in most cancers, but not some gastrointestinal cancers. The potential mechanism underlying this relationship is worthy of further study. Finally, B7-H3 has different functions in different cancers, which may reflect actions via different receptors. Inevitably, there are some limitations to our study. First, the numbers of studies and patients included in the PFS, RFS and OS subgroup analyses were relatively small, which could have resulted in heterogeneity. Second, the studies included in our analysis were all published in English, and thus some studies in other languages were omitted. Third, some studies did not provide accurate HRs for analysis, and we calculated HRs and 95\% CIs based on survival curves, which resulted in small statistical errors. Finally, the cut-off values for B7-H3 expression differed among the included studies, which could have affected the stability of the results.

In conclusion, our results revealed that B7-H3 expression is associated with poor prognosis in most human solid tumors, suggesting that B7-H3 may be a useful prognostic biomarker and a promising new therapeutic target for solid tumors. In view of the limitations of our analysis, this conclusion should be considered cautiously. Some remaining questions and issues to be addressed in the future include identification of the exact receptors for $\mathrm{B} 7-\mathrm{H} 3$ and the establishment of standard assessment criteria. Accordingly, further prospective multicenter studies with larger samples will be needed to determine the role of B7-H3 in both the prognosis of and targeted therapy for various cancers. 
A

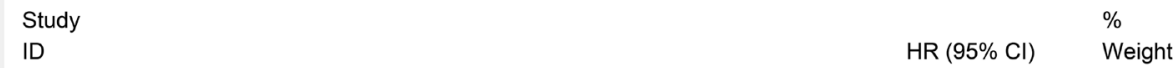

Yue-Hua Xu (2010)

Andreas Brunner (2012)

Changping Wu (2006)

Chenglin Huang (2015)

Jung-Tsu Chen (2015)

Lihua Xu (2013)

Ling Wang (2013)

Ling Wang (2016)

Lujun Chen (2015)

Mao Yong (2013)

Martin Loos (2009)

N. Maeda (2014)

Taiwei Sun (2012)

Takaaki Arigami (2011)

Xingxing Zang (2010)

Yan Chen (2014)

Yingjie Jin (2015)

Yixiang Mao (2014)

Bin Zhou (2014)

Ingebrigtsen VA (2014)

Stephen A. Boorjian (2008)

Jianxiang Song (2016)

Takehiko Fukuda (2016)

Liu CL (2016)

Kentaro Inamura (2017)

Dan Luo (2017)

Overall (I-squared $=47.1 \%, p=0.005)$

NOTE: Weights are from random effects analysis

.0118

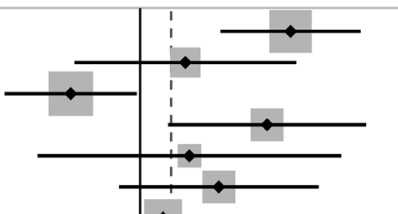

$9.30(3.29,26.28) 2.34$

$1.95(0.38,10.14) 1.08$

$0.36(0.13,0.95) \quad 2.55$

$6.57(1.51,28.50) 1.32$

$2.08(0.22,19.77) \quad 0.60$

$3.21(0.73,14.12) 1.30$

$1.40(0.41,4.83) \quad 1.77$

$6.27(1.82,21.58) 1.77$

$1.56(1.04,2.35) \quad 6.76$

$1.21(0.51,2.86) \quad 3.07$

$0.64(0.01,35.10) \quad 0.20$

$3.12(0.53,18.25) \quad 0.95$

$1.19(0.76,1.86) \quad 6.28$

$1.56(1.01,2.41) \quad 6.43$

$2.65(1.11,6.33) \quad 3.04$

$1.17(0.59,2.33) \quad 4.14$

$1.26(0.71,2.22) \quad 5.10$

$2.26(1.21,4.23) \quad 4.59$

$1.54(0.59,4.02) \quad 2.63$

$0.90(0.58,1.40) \quad 6.40$

$1.11(0.79,1.56) \quad 7.55$

$1.89(1.06,3.34) \quad 5.06$

$1.84(0.93,3.63) \quad 4.18$

$1.77(0.98,3.18) \quad 4.92$

$1.79(1.29,2.48) \quad 7.70$

$1.45(1.10,1.92) \quad 8.28$

$1.58(1.32,1.90) \quad 100.00$

84.6

B

Study

ID

$\mathrm{HR}(95 \% \mathrm{Cl}) \quad$ Weight

Andreas Brunner (2012)

Chenglin Huang (2015)

Jung-Tsu Chen (2015)

Lihua Xu (2013)

Ling Wang (2013)

Ling Wang (2016)

Lujun Chen (2015)

Mao Yong (2013)

Martin Loos (2009)

N. Maeda (2014)

Taiwei Sun (2012)

Takaaki Arigami (2011)

Xingxing Zang (2010)

Yan Chen (2014)

Yingjie Jin (2015)

Yixiang Mao (2014)

Bin Zhou (2014)

Ingebrigtsen VA (2014)

Stephen A. Boorjian (2008)

Jianxiang Song (2016)

Takehiko Fukuda (2016)

Liu CL (2016)

Kentaro Inamura (2017)

Dan Luo (2017)

Overall $(I-$ squared $=15.4 \%, p=0.248)$
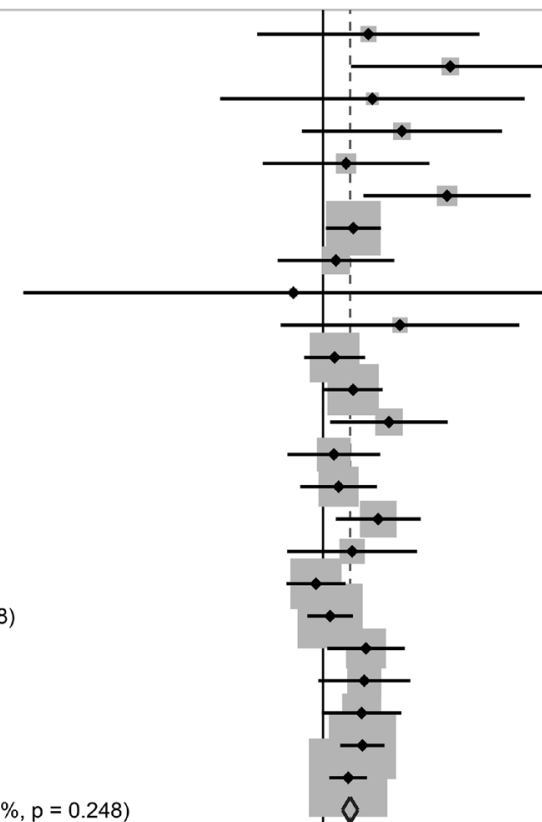

$1.95(0.38,10.14) \quad 0.49$

$6.57(1.51,28.50) \quad 0.62$

$2.08(0.22,19.77) \quad 0.26$

$3.21(0.73,14.12) \quad 0.61$

$1.40(0.41,4.83) \quad 0.87$

$6.27(1.82,21.58) \quad 0.87$

$1.56(1.04,2.35) \quad 8.02$

$1.21(0.51,2.86) \quad 1.79$

$0.64(0.01,35.10) \quad 0.08$

$3.12(0.53,18.25) \quad 0.43$

$1.19(0.76,1.86) \quad 6.56$

$1.56(1.01,2.41) \quad 6.98$

$2.65(1.11,6.33) \quad 1.76$

$1.17(0.59,2.33) \quad 2.83$

$1.26(0.71,2.22) \quad 4.13$

$2.26(1.21,4.23) \quad 3.39$

$1.54(0.59,4.02) \quad 1.45$

$0.90(0.58,1.40) \quad 6.91$

$1.11(0.79,1.56) \quad 11.53$

$1.89(1.06,3.34) \quad 4.06$

$1.84(0.93,3.63) \quad 2.87$

$1.77(0.98,3.18) \quad 3.86$

$1.79(1.29,2.48) \quad 12.43$

$1.45(1.10,1.92) \quad 17.17$

$1.49(1.33,1.67) \quad 100.00$

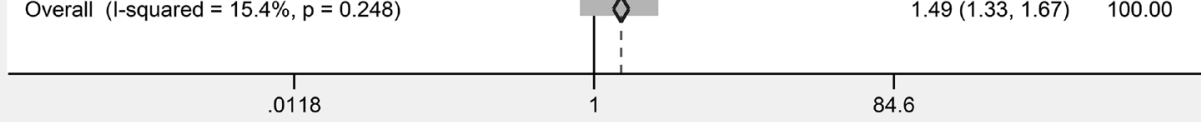

Figure 2: Forest plots of studies evaluating hazard ratios (HRs) of B7-H3 for overall survival. (A) Summary of all twentysix studies with regard to overall survival; the estimate was $1.58(1.32-1.90)$ using a random effects model. (B) The exclusion of two studies $[6,12]$ resulted in no heterogeneity; the estimate was $1.49(1.33-1.67)$ using a fixed effects model. 
A

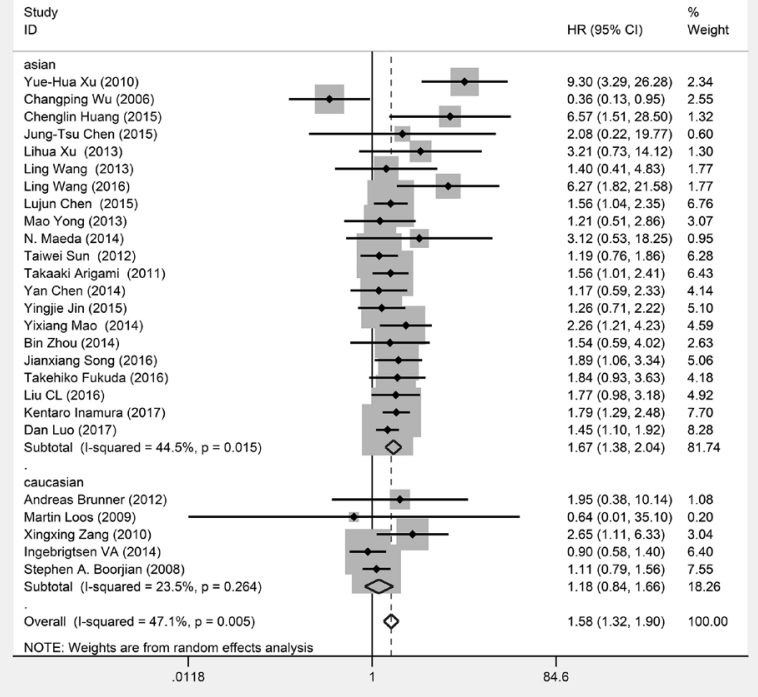

B
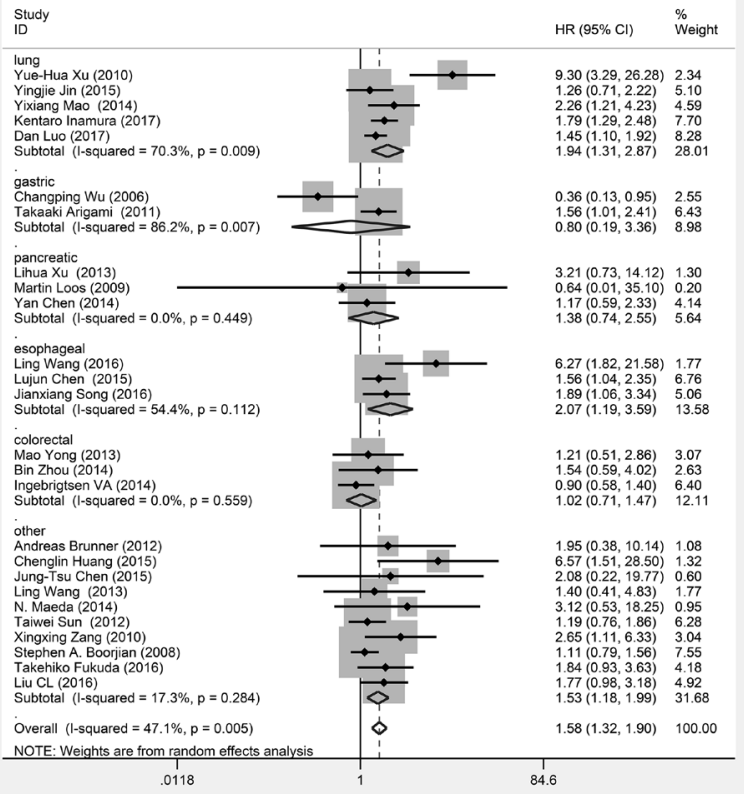

C

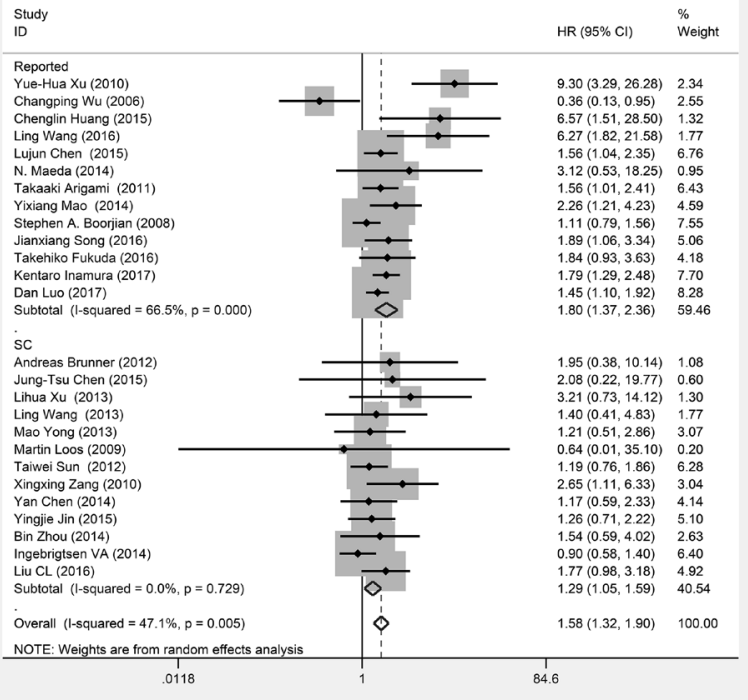

Figure 3: Forest plots of studies evaluating hazard ratios (HRs) of B7-H3 for overall survival in different subgroups. (A) Subgroup analysis by ethnicity. (B) Subgroup analysis by cancer type. (C) Subgroup analysis by HR source. 
Xingxing Zang (2007)

Yishan Liu (2012)

Jianxiang Song (2016)

Stephen A. Boorjian (2008)

Overall $(I-$ squared $=59.1 \%, p=0.062)$

NOTE: Weights are from random effects analysis

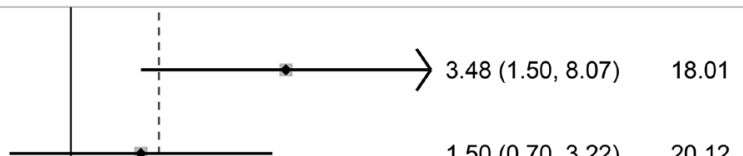

$1.50(0.70,3.22) \quad 20.12$

$1.89(1.06,3.34) \quad 26.33$

$1.11(0.79,1.56) \quad 35.54$

$1.67(1.05,2.65) \quad 100.00$

Figure 4: Forest plots of studies evaluating hazard ratios (HRs) of B7-H3 for PFS.

Study

ID

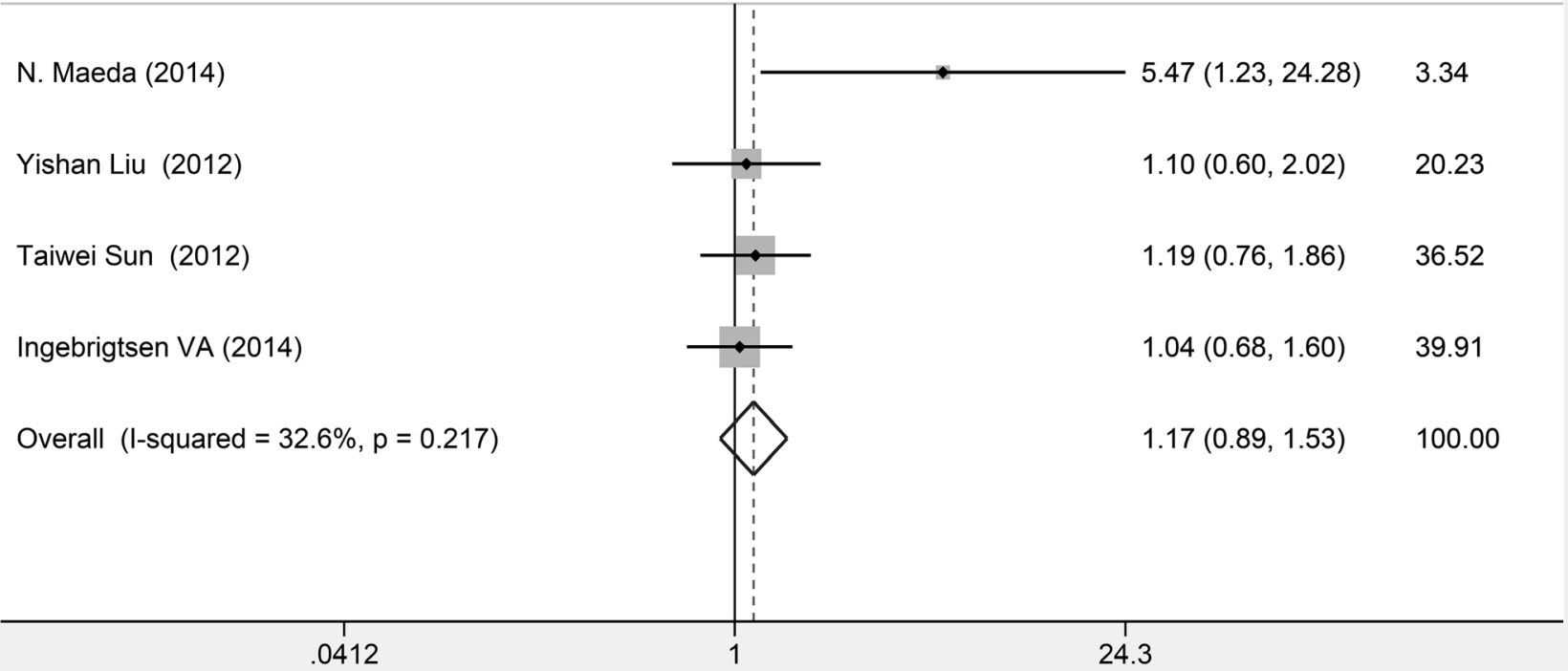

$\mathrm{HR}(95 \% \mathrm{Cl}) \quad$ Weight 


\section{MATERIALS AND METHODS}

\section{Literature search}

The PubMed and Embase databases were comprehensively searched until 11 February 2017. In this meta-analysis, the Preferred Reporting Items for Systematic Reviews and Meta-Analyses (PRISMA) statement was followed [23]. The key words "B7-H3 OR CD276 OR B7 homolog 3 protein OR B7H3” AND "cancer OR tumor OR tumour OR neoplasm or carcinoma" AND "prognosis OR prognostic OR outcome OR survival OR fellow-up" were used to identify eligible studies. To identify additional potential studies, the reference lists of retrieved studies and reviews were also searched manually.

\section{Eligibility criteria}

Studies were included in our meta-analysis if they met the following criteria: (1) studies focusing on B7H3 expression and survival outcome, and (2) studies published as a full paper in English. Studies were excluded according to the following criteria: (1) reviews, letters, case reports, conference abstracts and laboratory studies; (2) studies with duplicate data or repeated analysis; (3) studies lacking sufficient information for further analysis; and (4) studies of hematological malignancies (because these cancers have unique mechanisms for tumorigenesis and metastasis). PubMed and Embase were searched independently by two authors (X. Zhang and C. Fang). For dual publications, the most detailed and informative study was selected for inclusion in the metaanalysis; unpublished literature, conference proceedings, dissertations and trial registries were excluded.

\section{Data extraction and quality assessment}

The following information was extracted independently by two investigators: first author's name, publication year, country of origin, cancer type, number of patients, gender and age of patients, detection method, cut-off value, statistical method for survival analysis, occurrence of B7-H3 expression, and HRs with corresponding $95 \%$ CIs for overall survival (OS), and/ or progression-free survival (PFS), and/or recurrencefree survival (RFS). If a study reported results from both univariate and multivariate analyses, the data for the multivariate analysis were selected. If HRs and CIs were not reported, the outcomes of interest were independently calculated using Kaplan-Meier curves by two investigators according to methods proposed by Tierney et al. [56]. Both investigators compared their datasets and combined the results to yield a final dataset. Disagreements were resolved in a consensus meeting.

Each of the 28 eligible studies was evaluated for methodological quality according to the Newcastle-Ottawa
Quality Assessment Scale (NOS) [57]. The mean value of all included studies was a score of 6.89 (ranging from 5 to 8) (Supplementary Tables 1 and 2), indicating high quality and good methodology. Therefore, all studies were included in the next meta-analysis.

\section{Statistical analysis}

HRs and corresponding 95\% CIs obtained from the selected studies were used to calculate pooled HRs. Statistical heterogeneity was tested using the chi-square test, and the $I^{2}$ statistic was used to assess the extent of statistical heterogeneity. If the $P$ value was more than 0.1 for the chi-square test AND $I^{2}$ was lower than $50 \%$, indicating low heterogeneity, then a fixed effects model (the Mantel-Haenszel method) was used to calculate the pooled effect. Otherwise, a random effects model (the DerSimonian and Laird method) was used. Subgroup analyses were performed to explore the source of any identified heterogeneity, and sensitivity analyses were used to confirm the stability of the pooled results and to identify possible explanations for the observed heterogeneity. Publication bias was depicted by funnel plots and statistically assessed by Begg's and Egger's tests (with $P<0.05$ indicating significant publication bias). Statistical analysis was performed using STATA 12.0 software. A $P$ value of less than 0.05 was defined as statistically significant. All $P$ values were two-sided.

\section{Abbreviations}

OS: overall survival; PFS: progression-free survival; RFS: recurrence-free survival; HR: hazard ratio; CI: confidence interval; NSCLC: non-small-cell lung cancer; UCB: urothelial carcinoma of the bladder; RCC: renal cell carcinoma; IHC: immunohistochemistry; IRS: immunoreactivity score; IHS: immunohistochemical score; qRT-PCR: quantitative real-time fluorescence polymerase chain reaction; ELISA: enzyme-linked immunosorbent assay; NR: no report; SC: survival curve; PD: $P$ value for subgroup difference; NOS: NewcastleOttawa Quality Assessment Scale.

\section{Author contributions}

Conceived and designed the experiments: ZX HJ. Performed the experiments: ZX FC JF. Analyzed the data: ZG ZX. Contributed reagents/materials/analysis tools: ZG WL. Wrote the paper: ZX.

\section{ACKNOWLEDGMENTS AND FUNDING}

We thank all the investigators involved in the studies included in this meta-analysis. This work was supported by grants from the National Natural Science Foundation of China (81272839; 81472401). 


\section{CONFLICTS OF INTEREST}

The authors declare no conflicts of interest.

\section{REFERENCES}

1. Siegel R, Naishadham D, Jemal A. Cancer statistics, 2013. CA Cancer J Clin. 2013; 63:11-30. https://doi.org/10.3322/ caac. 21166.

2. Chapoval AI, Ni J, Lau JS, Wilcox RA, Flies DB, Liu D, Dong H, Sica GL, Zhu G, Tamada K, Chen L. B7-H3: a costimulatory molecule for $\mathrm{T}$ cell activation and IFNgamma production. Nat Immunol. 2001; 2:269-274. https:// doi.org/10.1038/85339.

3. Wang L, Kang FB, Shan BE. B7-H3-mediated tumor immunology: friend or foe? Int J Cancer. 2014; 134:2764 2771. https://doi.org/10.1002/ijc.28474.

4. Wang J, Chong KK, Nakamura Y, Nguyen L, Huang SK, Kuo C, Zhang W, Yu H, Morton DL, Hoon DS. B7-H3 associated with tumor progression and epigenetic regulatory activity in cutaneous melanoma. J Invest Dermatol. 2013; 133:2050-2058. https://doi.org/10.1038/jid.2013.114.

5. Zhou Z, Luther N, Ibrahim GM, Hawkins C, Vibhakar R, Handler MH, Souweidane MM. B7-H3, a potential therapeutic target, is expressed in diffuse intrinsic pontine glioma. J Neurooncol. 2013; 111:257-264. https://doi. org/10.1007/s11060-012-1021-2.

6. Xu YH, Zhang GB, Wang JM, Hu HC. B7-H3 and CD133 expression in non-small cell lung cancer and correlation with clinicopathologic factors and prognosis. Saudi Med J. 2010; 31:980-986.

7. Yamato I, Sho M, Nomi T, Akahori T, Shimada K, Hotta K, Kanehiro H, Konishi N, Yagita H, Nakajima Y. Clinical importance of B7-H3 expression in human pancreatic cancer. Br J Cancer. 2009; 101:1709-1716. https://doi. org/10.1038/sj.bjc.6605375.

8. Crispen PL, Sheinin Y, Roth TJ, Lohse CM, Kuntz SM, Frigola $\mathrm{X}$, Thompson $\mathrm{RH}$, Boorjian SA, Dong $\mathrm{H}$, Leibovich BC, Blute ML, Kwon ED. Tumor cell and tumor vasculature expression of B7-H3 predict survival in clear cell renal cell carcinoma. Clin Cancer Res. 2008; 14:5150-5157. https://doi.org/10.1158/1078-0432.ccr-08-0536.

9. Ingebrigtsen VA, Boye $\mathrm{K}$, Tekle $\mathrm{C}$, Nesland JM, Flatmark K, Fodstad O. B7-H3 expression in colorectal cancer: nuclear localization strongly predicts poor outcome in colon cancer. Int J Cancer. 2012; 131:2528-2536. https:// doi.org/10.1002/ijc. 27566.

10. Zang X, Sullivan PS, Soslow RA, Waitz R, Reuter VE, Wilton A, Thaler HT, Arul M, Slovin SF, Wei J, Spriggs DR, Dupont J, Allison JP. Tumor associated endothelial expression of $\mathrm{B} 7-\mathrm{H} 3$ predicts survival in ovarian carcinomas. Mod Pathol. 2010; 23:1104-1112. https://doi. org/10.1038/modpathol.2010.95.
11. Arigami T, Narita N, Mizuno R, Nguyen L, Ye X, Chung A, Giuliano AE, Hoon DS. B7-h3 ligand expression by primary breast cancer and associated with regional nodal metastasis. Ann Surg. 2010; 252:1044-1051. https://doi.org/10.1097/ SLA.0b013e3181f1939d.

12. Wu CP, Jiang JT, Tan M, Zhu YB, Ji M, Xu KF, Zhao JM, Zhang GB, Zhang XG. Relationship between co-stimulatory molecule B7-H3 expression and gastric carcinoma histology and prognosis. World J Gastroenterol. 2006; 12:457-459.

13. Brunner A, Hinterholzer S, Riss P, Heinze G, Brustmann H. Immunoexpression of $\mathrm{B} 7-\mathrm{H} 3$ in endometrial cancer: relation to tumor T-cell infiltration and prognosis. Gynecol Oncol. 2012; 124:105-111. https://doi.org/10.1016/j. ygyno.2011.09.012.

14. Sun Y, Wang Y, Zhao J, Gu M, Giscombe R, Lefvert AK, Wang X. B7-H3 and B7-H4 expression in non-small-cell lung cancer. Lung Cancer. 2006; 53:143-151. https://doi. org/10.1016/j.lungcan.2006.05.012.

15. Zang X, Thompson RH, Al-Ahmadie HA, Serio AM, Reuter VE, Eastham JA, Scardino PT, Sharma P, Allison JP. B7-H3 and B7x are highly expressed in human prostate cancer and associated with disease spread and poor outcome. Proc Natl Acad Sci U S A. 2007; 104:19458-19463. https://doi.org/10.1073/pnas.0709802104.

16. Huang C, Zhou L, Chang X, Pang X, Zhang H, Zhang S. B7-H3, B7-H4, Foxp3 and IL-2 expression in cervical cancer: associations with patient outcome and clinical significance. Oncol Rep. 2016; 35:2183-2190. https://doi. org/10.3892/or.2016.4607.

17. Chen JT, Chen CH, Ku KL, Hsiao M, Chiang CP, Hsu TL, Chen $\mathrm{MH}$, Wong CH. Glycoprotein B7-H3 overexpression and aberrant glycosylation in oral cancer and immune response. Proc Natl Acad Sci U S A. 2015; 112:1305713062. https://doi.org/10.1073/pnas.1516991112.

18. Xu L, Ding X, Tan H, Qian J. Correlation between B7-H3 expression and matrix metalloproteinases 2 expression in pancreatic cancer. Cancer Cell Int. 2013; 13:81. https://doi. org/10.1186/1475-2867-13-81.

19. Wang L, Zhang Q, Chen W, Shan B, Ding Y, Zhang G, Cao N, Liu L, Zhang Y. B7-H3 is overexpressed in patients suffering osteosarcoma and associated with tumor aggressiveness and metastasis. PLoS One. 2013; 8:e70689. https://doi.org/10.1371/journal.pone.0070689.

20. Wang L, Cao NN, Wang S, Man HW, Li PF, Shan BE. Roles of coinhibitory molecules B7-H3 and B7-H4 in esophageal squamous cell carcinoma. Tumour Biol. 2016; 37:2961-2971. https://doi.org/10.1007/s13277-015-4132-5.

21. Chen L, Chen J, Xu B, Wang Q, Zhou W, Zhang G, Sun J, Shi L, Pei H, Wu C, Jiang J. B7-H3 expression associates with tumor invasion and patient's poor survival in human esophageal cancer. Am J Transl Res. 2015; 7:2646-2660.

22. Mao Y, Sun J, Wang WP, Zhang XG, Hua D. Clinical significance of costimulatory molecule B7-H3 expression 
on CD3(+) T cells in colorectal carcinoma. Chin Med J (Engl). 2013; 126:3035-3038.

23. Loos M, Hedderich DM, Ottenhausen M, Giese NA, Laschinger M, Esposito I, Kleeff J, Friess H. Expression of the costimulatory molecule B7-H3 is associated with prolonged survival in human pancreatic cancer. BMC Cancer. 2009; 9:463. https://doi.org/10.1186/1471-2407-9-463.

24. Maeda N, Yoshimura K, Yamamoto S, Kuramasu A, Inoue M, Suzuki N, Watanabe Y, Maeda Y, Kamei R, Tsunedomi R, Shindo Y, Inui M, Tamada K, et al. Expression of B7-H3, a potential factor of tumor immune evasion in combination with the number of regulatory $\mathrm{T}$ cells, affects against recurrence-free survival in breast cancer patients. Ann Surg Oncol. 2014; 21 Suppl 4:S546-S554. https://doi.org/10.1245/s10434-014-3564-2.

25. Sun TW, Gao Q, Qiu SJ, Zhou J, Wang XY, Yi Y, Shi JY, Xu YF, Shi YH, Song K, Xiao YS, Fan J. B7-H3 is expressed in human hepatocellular carcinoma and is associated with tumor aggressiveness and postoperative recurrence. Cancer Immunol Immunother. 2012; 61:2171-2182. https://doi. org/10.1007/s00262-012-1278-5.

26. Arigami T, Uenosono Y, Hirata M, Yanagita S, Ishigami S, Natsugoe S. B7-H3 expression in gastric cancer: a novel molecular blood marker for detecting circulating tumor cells. Cancer Sci. 2011; 102:1019-1024. https://doi. org/10.1111/j.1349-7006.2011.01877.x.

27. Chen Y, Sun J, Zhao H, Zhu D, Zhi Q, Song S, Zhang L, He S, Kuang Y, Zhang Z, Li D. The coexpression and clinical significance of costimulatory molecules B7-H1, B7-H3, and B7-H4 in human pancreatic cancer. Onco Targets Ther. 2014; 7:1465-1472. https://doi.org/10.2147/ott.s66809.

28. Jin Y, Zhang P, Li J, Zhao J, Liu C, Yang F, Yang D, Gao A, Lin W, Ma X, Sun Y. B7-H3 in combination with regulatory $\mathrm{T}$ cell is associated with tumor progression in primary human non-small cell lung cancer. Int J Clin Exp Pathol. 2015; 8:13987-13995.

29. Liu Y, Vlatkovic L, Saeter T, Servoll E, Waaler G, Nesland JM, Giercksky KE, Axcrona K. Is the clinical malignant phenotype of prostate cancer a result of a highly proliferative immune-evasive B7-H3-expressing cell population? Int J Urol. 2012; 19:749-756. https://doi. org/10.1111/j.1442-2042.2012.03017.x.

30. Mao Y, Li W, Chen K, Xie Y, Liu Q, Yao M, Duan W, Zhou X, Liang R, Tao M. B7-H1 and B7-H3 are independent predictors of poor prognosis in patients with non-small cell lung cancer. Oncotarget. 2015; 6:3452-3461. https://doi.org/10.18632/oncotarget.3097.

31. Bin Z, Guangbo Z, Yan G, Huan Z, Desheng L, Xueguang Z. Overexpression of $\mathrm{B} 7-\mathrm{H} 3$ in $\mathrm{CD} 133+$ colorectal cancer cells is associated with cancer progression and survival in human patients. J Surg Res. 2014; 188:396-403. https://doi. org/10.1016/j.jss.2014.01.014.

32. Boorjian SA, Sheinin Y, Crispen PL, Farmer SA, Lohse CM, Kuntz SM, Leibovich BC, Kwon ED, Frank I. T-cell coregulatory molecule expression in urothelial cell carcinoma: clinicopathologic correlations and association with survival. Clin Cancer Res. 2008; 14:4800-4808. https://doi.org/10.1158/1078-0432.ccr-08-0731.

33. Ingebrigtsen VA, Boye K, Nesland JM, Nesbakken A, Flatmark K, Fodstad O. B7-H3 expression in colorectal cancer: associations with clinicopathological parameters and patient outcome. BMC Cancer. 2014; 14:602. https:// doi.org/10.1186/1471-2407-14-602.

34. Luo D, Xiao H, Dong J, Li Y, Feng G, Cui M, Fan S. B7-H3 regulates lipid metabolism of lung cancer through SREBP1mediated expression of FASN. Biochem Biophys Res Commun. 2017; 482:1246-1251. https://doi.org/10.1016/j. bbrc.2016.12.021.

35. Song J, Shi W, Zhang Y, Sun M, Liang X, Zheng S. Epidermal growth factor receptor and B7-H3 expression in esophageal squamous tissues correlate to patient prognosis. Onco Targets Ther. 2016; 9:6257-6263. https://doi. org/10.2147/ott.s111691.

36. Fukuda T, Kamai T, Masuda A, Nukui A, Abe H, Arai K, Yoshida K. Higher preoperative serum levels of PD-L1 and B7-H4 are associated with invasive and metastatic potential and predictable for poor response to VEGF-targeted therapy and unfavorable prognosis of renal cell carcinoma. Cancer Med. 2016; 5:1810-1820. https://doi.org/10.1002/ cam4.754.

37. Liu CL, Zang XX, Huang H, Zhang H, Wang C, Kong YL, Zhang HY. The expression of B7-H3 and B7-H4 in human gallbladder carcinoma and their clinical implications. Eur Rev Med Pharmacol Sci. 2016; 20:4466-4473.

38. Inamura K, Yokouchi Y, Kobayashi M, Sakakibara R, Ninomiya H, Subat S, Nagano H, Nomura K, Okumura S, Shibutani T, Ishikawa Y. Tumor B7-H3 (CD276) expression and smoking history in relation to lung adenocarcinoma prognosis. Lung Cancer. 2017; 103:44-51. https://doi. org/10.1016/j.lungcan.2016.11.013.

39. Tekle C, Nygren MK, Chen YW, Dybsjord I, Nesland JM, Maelandsmo GM, Fodstad O. B7-H3 contributes to the metastatic capacity of melanoma cells by modulation of known metastasis-associated genes. Int J Cancer. 2012; 130:2282-2290. https://doi.org/10.1002/ijc.26238.

40. Zhao X, Li DC, Zhu XG, Gan WJ, Li Z, Xiong F, Zhang ZX, Zhang GB, Zhang XG, Zhao H. B7-H3 overexpression in pancreatic cancer promotes tumor progression. Int $\mathrm{J}$ Mol Med. 2013; 31:283-291. https://doi.org/10.3892/ ijmm.2012.1212.

41. Prasad DV, Nguyen T, Li Z, Yang Y, Duong J, Wang Y, Dong C. Murine B7-H3 is a negative regulator of T cells. J Immunol. 2004; 173:2500-2506.

42. Fukushima A, Sumi T, Fukuda K, Kumagai N, Nishida T, Yamazaki T, Akiba H, Okumura K, Yagita H, Ueno H. B7-H3 regulates the development of experimental allergic conjunctivitis in mice. Immunol Lett. 2007; 113:52-57. https://doi.org/10.1016/j.imlet.2007.07.011.

43. Ling V, Wu PW, Spaulding V, Kieleczawa J, Luxenberg D, Carreno BM, Collins M. Duplication of primate and rodent 
B7-H3 immunoglobulin V- and C-like domains: divergent history of functional redundancy and exon loss. Genomics. 2003; 82:365-377.

44. Chen YW, Tekle C, Fodstad O. The immunoregulatory protein human $\mathrm{B} 7 \mathrm{H} 3$ is a tumor-associated antigen that regulates tumor cell migration and invasion. Curr Cancer Drug Targets. 2008; 8:404-413.

45. Xu H, Cheung IY, Guo HF, Cheung NK. MicroRNA miR29 modulates expression of immunoinhibitory molecule B7-H3: potential implications for immune based therapy of human solid tumors. Cancer Res. 2009; 69:6275-6281. https://doi.org/10.1158/0008-5472.can-08-4517.

46. Devarajan E, Huang S. STAT3 as a central regulator of tumor metastases. Curr Mol Med. 2009; 9:626-633.

47. Quandt D, Fiedler E, Boettcher D, Marsch W, Seliger B. B7-h4 expression in human melanoma: its association with patients' survival and antitumor immune response. Clin Cancer Res. 2011; 17:3100-3111. https://doi. org/10.1158/1078-0432.ccr-10-2268.

48. Boland JM, Kwon ED, Harrington SM, Wampfler JA, Tang H, Yang P, Aubry MC. Tumor B7-H1 and B7-H3 expression in squamous cell carcinoma of the lung. Clin Lung Cancer. 2013; 14:157-163. https://doi.org/10.1016/j. cllc.2012.05.006.

49. Brahmer JR, Tykodi SS, Chow LQ, Hwu WJ, Topalian SL, Hwu P, Drake CG, Camacho LH, Kauh J, Odunsi K, Pitot HC, Hamid O, Bhatia S, et al. Safety and activity of anti-PD-L1 antibody in patients with advanced cancer. N Engl J Med. 2012; 366:2455-2465. https://doi.org/10.1056/NEJMoa1200694.

50. Hodi FS, O'Day SJ, McDermott DF, Weber RW, Sosman JA, Haanen JB, Gonzalez R, Robert C, Schadendorf D, Hassel JC, Akerley W, van den Eertwegh AJ, Lutzky J, et al. Improved survival with ipilimumab in patients with metastatic melanoma. N Engl J Med. 2010; 363:711-723. https://doi.org/10.1056/NEJMoa1003466.
51. Topalian SL, Hodi FS, Brahmer JR, Gettinger SN, Smith DC, McDermott DF, Powderly JD, Carvajal RD, Sosman JA, Atkins MB, Leming PD, Spigel DR, Antonia SJ, et al. Safety, activity, and immune correlates of anti-PD-1 antibody in cancer. N Engl J Med. 2012; 366:2443-2454. https://doi.org/10.1056/NEJMoa1200690.

52. Janakiram M, Shah UA, Liu W, Zhao A, Schoenberg MP, Zang X. The third group of the B7-CD28 immune checkpoint family: HHLA2, TMIGD2, B7x, and B7-H3. Immunol Rev. 2017; 276:26-39. https://doi.org/10.1111/imr.12521.

53. Gadiot J, Hooijkaas AI, Kaiser AD, van Tinteren H, van Boven H, Blank C. Overall survival and PD-L1 expression in metastasized malignant melanoma. Cancer. 2011; 117:2192-2201. https://doi.org/10.1002/cncr.25747.

54. Muenst S, Schaerli AR, Gao F, Daster S, Trella E, Droeser RA, Muraro MG, Zajac P, Zanetti R, Gillanders WE, Weber WP, Soysal SD. Expression of programmed death ligand 1 (PD-L1) is associated with poor prognosis in human breast cancer. Breast Cancer Res Treat. 2014; 146:15-24. https://doi.org/10.1007/s10549-014-2988-5.

55. Kronig H, Falchner KJ, Odendahl M, Brackertz B, Conrad H, Muck D, Hein R, Blank C, Peschel C, Haller B, Schulz $\mathrm{S}$, Bernhard H. PD-1 expression on Melan-A-reactive T cells increases during progression to metastatic disease. Int J Cancer. 2012; 130:2327-2336. https://doi.org/10.1002/ ijc. 26272 .

56. Tierney JF, Stewart LA, Ghersi D, Burdett S, Sydes MR. Practical methods for incorporating summary time-to-event data into metaanalysis. Trials. 2007; 8:16.

57. Wells G, Shea B, O'Connell D, Peterson J, Welch V, Losos M, Tugwell P. The Newcastle-Ottawa Scale (NOS) for assessing the quality of nonrandomised studies in meta-analyses. Ottawa, Ontario: Ottawa Hospital Research Institute; 2014. 